\title{
Machado-Joseph disease type 1
}

INSERM

\section{Source}

INSERM. (1999). Orphanet: an online rare disease and orphan drug data base. MachadoJoseph disease type 1. ORPHA:276238

Machado-Joseph disease type 1 is a rare, usually severe subtype of Machado-Joseph disease (SCA3/MJD, see this term) characterized by the presence of marked pyramidal and extrapyramidal signs. 